\title{
IPO Pricing Analysis of Discrete Information Structure
}

\author{
Yunzhao Lu \\ Fuzhou University of International Studies and Trade \\ Fuzhou, China 350200
}

\begin{abstract}
Because of the different size and research strength of each institutional investor, the quantity and quality of market information are different, that is, the existence of heterogeneous institutional investors makes the distribution of new stock pricing information more complex. Issuers need to determine the corresponding pricing methods under different information distribution conditions, that is, unified pricing or differential pricing, and based on conditional probability to determine the corresponding price level, so as to maximize the issue income; Because of the participation of retail investors and the existence of callback mechanism, the under-pricing phenomenon in some cases is eliminated.
\end{abstract}

Keywords-IPO; small and medium investors; mechanism design; information asymmetry

\section{INTRODUCTION}

There are differences in the quantity and quality of the market information that the institutional investors are different in scale and research strength. The existence of the heterogeneous institutional investors makes the distribution of the IPO pricing information more complex. This chapter comprehensively considers the real market environment factors such as two phase inquiry, return mechanism and distribution cost. Under different information distribution conditions, the optimal pricing level and expected income are determined by using conditional probability and conditional expectation model, moreover, we expect that the expected return of differential pricing is greater than that of unified pricing; As a result of the participation of retail investors and the existence of the callback mechanism, the phenomenon of under-pricing has been eliminated. From the perspective of social benefits, we determine the pricing level when the total return is the maximum and give the largest total social return.

Information asymmetry plays an important role in the pricing process of IPO. In the IPO market, there are four main types of subjects: issuers, investment banks, institutional investors, retail investors. They all have their own advantages and disadvantages, such as the issuer knows more clearly their own business and financial situation; Investment banks know better about capital market demand for stocks; institutional investors have more comprehensive research on competitors for Industry and listed companies than issuers and investment banks, which can more objectively evaluate the issuer's competitiveness and valuation; retail investors are generally considered to have no information advantages. Many of the existing literatures focus on the different information structures among the four subjects: for example, institutional investors have information advantages over issuers and investment banks, or believe that investment banks have more information on market demand than institutional investors.

Most of the literatures agree that institutional investors are information symmetric or homogeneous. Sherman and Titman (2002 and Bierbaum and Grimm (2006) assume that institutional investors have certain valuation information but the quality of information is different. That is, under the assumption that institutional investors are information asymmetry or heterogeneity. Leite (2006) is based on the assumption that informed investors have heterogeneous information. Leite (2007) explained under-pricing from the perspective of reverse selection under the same hypothesis. In the research of Leite (2006 / 2007) and Bierbaum and Grimm (2006), retail investors did not appear in the new share purchase process, on the basis of the participation of retail investors, this paper studies the pricing strategy of issuers and the income difference. Malakhov (2012) discusses the influence of retail investors in IPO, and concludes that the participation of retail investors can increase the income of issuers. The above documents do not take into account the issue cost. We think that the issue cost will affect the issuer's income and thus take this factor into account.

This paper assumes that IPO is carried out in two stages, which is similar to the two-stage inquiry system in China's A-share main board market. In the initial inquiry stage, the institutional investors report their purchase intention according to their own information and decide whether to participate in the second stage offline purchase. Retail investors will apply online in the second phase, while issuers will use the callback mechanism based on the requisition. Under the above rules, the issuer carries out unified pricing and differential pricing, and compares the revenue under different pricing strategies.

The innovation of this paper is to assume that institutional investors are heterogeneous while introducing retail investors, and considering the real trading system environment of A share market in China and considering the issue cost, under different information distribution conditions, The optimal allocation and pricing rules of new shares are 
analyzed by using conditional probability and conditional expectation models.

\section{MODEL HYPOTHESIS}

The market environment of IPO usually consists of four kinds of market entities: issuer, investment bank, institutional investor and retail investor. This paper assumes that the issuer and the investment bank share the same information structure and interest demand that is to pursue the maximization of the issue income, so this paper combines the two market entities and expresses them as issuers.

Assume that the issuer intends to issue a fixed number of shares, not out of the ordinary, assuming that the number is 1 . $5 \%$. A listed company may be a well-run, financially sound company with a high valuation $V_{h}$; or a company with an average investment value, with the market offering only a low valuation $V_{l}$. Assuming that the company is a high valuation probability $P_{h}$, the probability of a low valuation company is $P_{l}=1-P_{h}$. The above priori distribution is public information.

There are two kinds of institutional investors in the market. Because of the difference of the scale and the research strength among the institutions, the quantity and quality of the market information are different, so the accuracy of the research and judgment of the company valuation is different. That is, the core assumption of this paper: institutional investors are heterogeneous. After investigating and analyzing the listed companies, the institutional investors have some information about the high or low quality of the companies, and come to the conclusion that the companies are "good" or "bad", we use the "good" signal. $g$ or "bad" signal b represent, suppose that class I institution have signals $s_{i} \in\left\{g_{i}, b_{i}\right\}$, and $P\left(g_{i} \mid V_{h}\right)=P\left(b_{i} \mid V_{l}\right)=\lambda_{i}, i=1,2$, in $\frac{1}{2}<\lambda_{1}<\lambda_{2} \leq 1$, otherwise, the study of a institution would be meaningless. $g$ and $b$ are private signals, Only institutional investors themselves know. $P\left(g_{i} \mid V_{h}\right)$ when the company is highly valued, investor i probability of getting a "good" signal, that is ,the probability of an investor making an accurate judgment on the company, so the higher the $\lambda$ value, the more accurate the investor's signal is, the higher the quality of information. There are also a large number of retail investors, assuming they do not have private valuation information and are considered "hitchhikers" in the IPO market. This paper argues that they are homogeneous, so let's assume that the number of retail investors is 1 .

IPO is divided into two parts: online and offline biding, the proportion of online purchase is $\alpha$ mainly for retail investors. The proportion of offline placing is $1-\alpha$ for institutional investors. If the subscriptions are not enough to offline, back to online, the same online part can also be returned to offline.
Suppose both institutional and retail investors have no budget constraints, that is, they are able to absorb all the shares on their own, IPO adopts a two-stage inquiry mechanism and distinguishes between online and offline subscriptions, which is consistent with the Listing Rules of China's A-share motherboard market. In the first stage, only institutional investors participate. Institutional investors get signals or judge the quality of listed companies according to preliminary research. If Institutional investors get the signal, Institutional investors will continue to participate in the second stage of the offer; if Institutional investors get the signal, you will give up the offline purchase, and under the principle of fairness, institutional investors who give up the offline purchase will not be allowed to participate in the online purchase.

If the two types of institutional investors receive the signal in the first stage, they are not involved in the second phase of the purchase. The issuer cancels the IPO, and assumes that the issuer can have no cost to cancel the issue. This article believes that the company needs to do a lot of restructuring, guidance, preparation and other work before the application of IPO, It is necessary to pay a fixed listing cost that cannot be ignored and set it to $\mathrm{C}$. If the issue is successful and the issuing income is I, the issuer pays $\mathrm{kI}$, $0<K<1$ to the underwriter.

Finally, the market price $\mathrm{V}$ of the new shares is determined by the valuation of the institutional investors, and the institutional investors value the new shares according to the information they have, so the expected market price for the new shares is $E\left(V \mid s_{1}, s_{2}\right)$.

\section{MODEL ANALYSIS}

(1) When $s_{1}=b_{1}, s_{2}=b_{2}$, that is, all institutional investors believe that the proposed listed company has no investment value and thus does not enter the second phase of the application. According to regulations, the issue should be cancelled, at this point the issuer's income is $-C$, to pay the fixed cost of listing.

(2) When $s_{1}=g_{1}, s_{2}=b_{2}$ or $s_{1}=b_{1}, s_{2}=g_{2}$, only one institutional investor entered the second phase. Issuers need to determine the price of the issue and the amount of rationing to institutional investors and retail investors to maximize revenue. According to the hypothesis, after the first stage of inquiry, the number of institutional investors to enter the second stage of purchase and the type of information (or) are public information, but the quality of institutional investors' information is still private information.

At this point, the institutional investors are fully aware of the company's valuation based on public information and their own information, if $s_{1}=g_{1}, s_{2}=b_{2}$, then $V=V\left(g_{1}, b_{2}\right) ;$ if $s_{1}=b_{1}, s_{2}=g_{2}$, then $V=V\left(b_{1}, g_{2}\right)$;

Retail investors only know the number of signals received by institutional investors, but do not know the exact 
signal is $g_{1}$ or $g_{2}$, so retail investors get the conditional expectation value of the company based on public information $E V=\frac{p\left(g_{1}, b_{2}\right) V\left(g_{1}, b_{2}\right)+p\left(b_{1}, g_{2}\right) V\left(b_{1}, g_{2}\right)}{p\left(g_{1}, b_{2}\right)+p\left(b_{1}, g_{2}\right)}$

Owing to $p\left(g_{1} \mid V_{H}\right)<p\left(g_{2} \mid V_{H}\right)$ That is, the signals of the second group of investors are more accurate than the signals of the first type investors, so the market gives more weight to the signals of the second type investors when they are valued, that is,

$$
V\left(g_{1}, b_{2}\right)<V\left(b_{1}, g_{2}\right),
$$

And according to EV's expression,

$$
V\left(g_{1}, b_{2}\right)<E V<V\left(b_{1}, g_{2}\right) \text {. }
$$

\section{A. Analysis of Unified Pricing Mechanism}

Assume that in the first stage of institutional investors based on their own information reported purchase intention, the issuer immediately set a unified issue price, and do not care about the exact signals of institutional investors.

Set the issue price is $P_{o}$, apparently $E V<P_{o} \leq V\left(b_{1}, g_{2}\right)$ or $P_{o}=V\left(b_{1}, g_{2}\right)$

The impact on retail requisitions is the same, that is, they will not participate in the requisition, the effect of other pricing ranges of $P_{o}$ on the purchase behavior of institutional investors is similar, that is, because the model discussed in this paper is a discrete model, the investor's bidding strategy is equivalent to a piecewise function of pricing, that is, the price of an interval. Requisition behavior is the same, and the issuer to maximize income, will set the price in the range maximum. So the issuer has three optional issue prices, that is $V\left(g_{1}, b_{2}\right), E V, V\left(b_{1}, g_{2}\right)$.

(1) If $P_{o}=V\left(b_{1}, g_{2}\right)$, owing to $E V<P_{o}$, retail investors withdraw from requisition, Part of the online callback to offline, this moment, if $s_{1}=g_{1}, s_{2}=b_{2}$, so the institutional investor is valued at $V\left(g_{1}, b_{2}\right)<P_{o}$, issue failure, the issuer's income is $-C$; If $s_{1}=b_{1}, s_{2}=g_{2}$, So the institutional investor is valued at $V=V\left(b_{1}, g_{2}\right)=P_{o}$, Institutional investors participate in the requisition, and subscribe for all shares, income is 0 , the issue is successful, and the issuer's income is $(1-k) V\left(b_{1}, g_{2}\right)-C$.

Thus, under the pricing of $P_{o}=V\left(b_{1}, g_{2}\right)$, the issuer's expected return is

$$
\frac{p\left(b_{1}, g_{2}\right)(1-k) V\left(b_{1}, g_{2}\right)}{p\left(g_{1}, b_{2}\right)+p\left(b_{1}, g_{2}\right)}-C
$$

(2) Set $P_{o}=E V$ when $s_{1}=g_{1}, s_{2}=b_{2}$ the valuation of institutional investors is $V=V\left(g_{1}, b_{2}\right)<P_{o}$, Exit subscription, retail investors participate in the subscription and the expected return is 0 ; at this time the offline part of the callback to the online; because both online and offline sales are available at the same time, retail investors are unable to observe the subscription of institutional investors, so the retail investors absorb all the shares, and the ultimate realized benefit is $V\left(g_{1}, b_{2}\right)-P_{o}<0$, retail investors suffer winner's curse, the issuer's income is $(1-k) E V-C$; When $s_{1}=b_{1}, s_{2}=g_{2}$, Institutional investor valuation $V=V\left(b_{1}, g_{2}\right)>P_{o}$ retail investors and category II institutional investors both participate in the requisition. Retail investors are entitled to $\alpha$ share with a profit of $\alpha\left[V\left(b_{1}, g_{2}\right)-P_{o}\right]>0$, institutional Investor access $1-\alpha$ share, the income is $(1-\alpha)\left[V\left(b_{1}, g_{2}\right)-P_{o}\right]>0$, the issuer's income is $(1-k) E V-C$. Thus, under the pricing of $P_{o}=E V$, the expected return of the issuer is $(1-k) E V-C$.

(3) Set $P_{o}=V\left(g_{1}, b_{2}\right)$, retail investors and institutions are involved in the subscription, the issue must be successful. When $s_{1}=g_{1}, s_{2}=b_{2}$, retail income is $\alpha\left[V\left(g_{1}, b_{2}\right)-P_{o}\right]=0$; the earnings of institutional investors are $(1-\alpha)\left[V\left(g_{1}, b_{2}\right)-P_{o}\right]=0$; when $s_{1}=b_{1}, s_{2}=g_{2}$; retail income is $\alpha\left[V\left(b_{1}, g_{2}\right)-P_{o}\right]>0$; the earnings of institutional investors are $(1-\alpha)\left[V\left(b_{1}, g_{2}\right)-P_{o}\right]>0$.The expected return of the issuer is $(1-k) V\left(g_{1}, b_{2}\right)-C$.

Combined with the above analysis; and $V\left(g_{1}, b_{2}\right)<E V<V\left(b_{1}, g_{2}\right)$, easy to get

Theorem 3.1: when $s_{1}=g_{1}, s_{2}=b_{2}$ or $s_{1}=b_{1}, s_{2}=g_{2}$; when the issuer takes a unified price, set $P_{o}=E V$ maximum available income from issuance $(1-k) E V-C$; and the expected under-pricing rate is 0 .

Compared with most literature analysis, the expected under-pricing is greater than 0 , the expected under-pricing of this paper is 0 . Through the above analysis, it is not difficult to see that this result stems from the participation of retail investors without budgetary constraints, and set up the online and offline issuing and callback mechanism.

\section{B. Analysis of Differential Pricing Mechanisms}

Issuers make differential pricing between institutional and retail investors to maximize revenue, let $P_{R}$ and $P_{I}$ be prices for retail and institutional investors, respectively.

Theorem 3.2: under differential pricing strategy, the expected return of issuer is greater than that of uniform pricing. 
Prove: Since the expected value of new shares for retail investors is $\mathrm{EV}$, rational constraints require $P_{R} \leq E V$, so to maximize revenue, the issuer can set $P_{R}=E V$, and because the issue has a callback mechanism and retail investors have no budget constraints, So you can set $P_{I} \geq E V$, Otherwise, you can dial the part of the offline back to the online, issued with $P_{R}=E V$, so that pricing for institutional investors only needs to satisfy the rational constraints of institutional investors with high quality information,

$$
\text { Set } P_{I}=V\left(b_{1}, g_{2}\right) \text {. }
$$

Under such a price arrangement, when $s_{1}=g_{1}, s_{2}=b_{2}$, Institutional investor valuation $V\left(g_{1}, b_{2}\right)<P_{I}$, after the withdrawal, , Part of the offline back to the online, retail investors subscribe for all shares, And realize the benefits $V\left(g_{1}, b_{2}\right)-P_{R}<0$, suffer a winner's curse; the income of the issuer is 1

$$
(1-k) E V-C \text {; when } s_{1}=b_{1}, s_{2}=g_{2} \text {, institutional }
$$
investor valuation $V\left(b_{1}, g_{2}\right)=P_{I}$, subscribe $1-\alpha$ share The income is 0 , retail investors subscribe for $\alpha$ share, income is $\quad \alpha\left[V\left(b_{1}, g_{2}\right)-P_{R}\right]>0$, the issuer's income is $(1-k)\left[\alpha E V+(1-\alpha) V\left(b_{1}, g_{2}\right)\right]-C$.

So under differential pricing, due to incomplete information about the quality of the signal; the condition expected income of the issuer is $\frac{\left(p\left(g_{1}, b_{2}\right)+\alpha p\left(b_{1}, g_{2}\right)\right) E V}{p\left(g_{1}, b_{2}\right)+p\left(b_{1}, g_{2}\right)}+\frac{p\left(b_{1}, g_{2}\right)(1-\alpha) V\left(b_{1}, g_{2}\right)(1-k)}{p\left(g_{1}, b_{2}\right)+p\left(b_{1}, g_{2}\right)}-C$.

Because $^{E V<V\left(b_{1}, g_{2}\right)}$, obviously the upper formula is greater than $(1-k) E V-C$, that is, under the unified price of the expected issue income.

Clearly, this result is consistent with our economic intuition that discriminatory pricing brings more revenue to sellers.

(3) When $s_{1}=g_{1}, s_{2}=g_{2}$, Both types of institutional investors are willing to apply, so that corporate valuation becomes the public information of the market that is $V=V\left(g_{1}, g_{2}\right)$, issuers only need to satisfy the participation constraints of all investors, and set $P_{o}=V\left(g_{1}, g_{2}\right)$. Retail investors get $\alpha$ shares, and two types of institutional investors get $\frac{1-\alpha}{2}$ shares respectively, all investors realized returns of 0 , the issuer's income is $(1-k) V\left(g_{1}, g_{2}\right)-C$.

\section{CONCLUSION}

This paper assumes that there is information asymmetry between institutional investors and retail investors and between institutional investors and issuers as well as differences in information quality among institutional investors. And suppose that the issuing system in this paper is as similar as possible to the IPO pricing system in China's A-share market, such as the two-stage cumulative bidding inquiry system, the proportional placing system, purchase at the same time on the online and offline and callback system. This paper analyzes the pricing strategy of the issuer with fixed price and differential price, compares the issue income, and discusses the phenomenon of under-pricing.

However, there are only two types of institutional investors in this paper, the information structure is relatively simple and the model analysis is relatively easy. Further discussion can assume that there are three kinds of institutional investors, the information distribution is more complex, and will encounter problems such as adverse selection, so we can consider using signal screening and other contract design theory to analyze.

\section{REFERENCES}

[1] Why New Issues are Underpriced?. Rock K. The Journal of Finance . 1986,15: 187-212

[2] The optimality of uniform pricing in IPOs: an optimal auction approach. Moez Bennouri,Sonia Falconieri. Rev. Finance . 2008, 12:673-700

[3] How investment bankers determine the offer price and allocation of new issues. Lawrence M. Benveniste,Paul A. Spindt. The Journal of Finance . 1989, 24: 343-361

[4] An optimal IPO mechanism. Bruno Biais,Peter Bossaerts,JeanCharles Rochet. Rev. Econom. Stud . 2002, 69: 117-146

[5] A comparativeanalysis of IPO proceeds under alternative regulatoryenvironments. Benveniste L M,Wilhelm W J. The Journal of Finance . 1990, 28: 173-207

[6] Adverse selection, public information, and underpricing in IPOs[J] . Tore Leite. Journal of Corporate Finance . 2007 , 13:813-828

[7] Bookbuilding with heterogeneous investors[J] . Tore Leite. Journal of Financial Intermediation . 2005, 15: 235-253. 